\title{
IMPLEMENTASI EXTREME PROGRAMMING PADA SISTEM RESERVASI TIKET TRAVEL BERBASIS ANDROID DAN WEBSITE
}

\author{
Rizki Wahyudi ${ }^{1}$, Tri Astuti ${ }^{2}$, Aep Saprul Mujahid ${ }^{3}$ \\ ${ }^{1,2,3}$ Program Studi Teknik Informatika, STMIK Amikom Purwokerto \\ Email: ${ }^{1}$ rizkiw@amikompurwokerto.ac.id, ${ }^{2}$ tri_astuti@amikompurwokerto.ac.id, ${ }^{3}$ aepsaprul@gmail.com
}

(Naskah masuk: 06 Agustus 2018, diterima untuk diterbitkan: 29 Oktober 2018)

\begin{abstract}
Abstrak
Sektor transportasi merupakan sektor yang pertumbuhannya cukup menjanjikan, diantaranya Travel dan rental mobil merupakan bisnis layanan penyedia penyewaan mobil dan travel yang mengalami peningkatan jumlah permintaan setiap tahunnya. Untuk meningkatkan layanan kepada konsumen dibutuhkan inovasi agar dapat melakukan reservasi mobil tanpa harus datang langsung ke tempat penyewaan, namun tetap dapat memastikan kualitas dan kenyamanan, Dalam penelitian ini mengambil studi kasus PT. Qyta Trans Group sebuah perusahaan rental mobil, yang melayani rental mobil dan travel di Wilayah Jawa, Sistem yang dibangun memungkin kan konsumen memilih jenis mobil untuk sewa dan posisi tempat duduk untuk travel. Pengembangan sistem menggunakan Metode Extreme Programming, yang cocok dengan desain dan program yang berbasis object oriented yaitu Unified Modeling Langguage dan bahasa pemograman Java, dengan menggunakan Metode Extreme Programming juga dapat dioptimalkan komunikasi dengan user dan dalam proses pengembangan sistem dapat menggunakan tim kecil. Sistem yang dibangun berbasis Android dan Website. Aplikasi Android merupakan Aplikasi yang diperuntukkan bagi konsumen dan Website diperuntukkan bagi admin yang mengelola data user dan pemesanan. Aplikasi reservasi Android dapat dijalankan minimal pada Android versi Ice Cream Sandwich (ICS). Pengujian dilakukan dengan dua metode Alpha Testing dan Beta Testing. Hasil dari pengujian Alpha Testing menggunakan metode Black-box menguji fungsional sistem pada aplikasi Android yang hasilnya semua fungsi yang ada pada aplikasi Android dapat berjalan sesuai yang diharapkan. Sementara hasil pengujian Beta Testing terhadap aplikasi Android yang berhubungan langsung dengan konsumen menggunakan metode kuesioner hasilnya 79,15\% persen responden setuju aplikasi sudah layak di implementasikan. Aplikasi Android Untuk Reservasi dapat di download pada $u r l:$ https://bit.ly/2NRsitw.
\end{abstract}

Kata kunci: Sistem, Pemesanan Online, Reservasi Mobil,, Extreme Programminng, Program Berbasis Objek.

\section{IMPLEMENTATION OF EXTREME PROGRAMMING IN TRAVEL TICKET RESERVATION SYSTEM BASED ANDROID AND WEBSITE}

\begin{abstract}
The transportation sector is a sector that has quite promising growth, including Travel and car rental is a service business for car rental and travel providers who experience an increasing number of requests each year. To improve service to consumers, innovation is needed in order to make a car reservation without having to come directly to the rental place, but still be able to ensure quality and comfort. In this study took a case study of PT. Qyta Trans Group is a car rental company, which serves car rental and travel in the Java Region. The system built allows consumers to choose the type of car for rent and the position of the seat to travel. System development using the Extreme Programming Method, which matches the design and programs that are object oriented based on Unified Modeling Langguage and Java programming languages, using the Extreme Programming Method can also be optimized communication with the user and in the process of developing the system can use a small team. The system is built based on Android and the Website. Android application is an application that is intended for consumers and the Website is intended for administrators who manage user data and orders. Android reservation application can be run at a minimum on the Android version of Ice Cream Sandwich (ICS). Testing is done with two Alpha Testing and Beta Testing approaches. The results of the Alpha Testing test use the Black-box method to test the functional system on the Android application which results in all functions in the Android application can run as expected. While the Beta Testing test results on Android applications that are directly related to consumers using the result questionnaire method $79.15 \%$ of respondents agree the application is feasible to implement. The Android Application for Reservations can be downloaded in the url: https://bit.ly/2NRsitw.
\end{abstract}

Keywords: System, Online Booking, Car Reservation, Extreme Programming, Object Oriented Programming 


\section{PENDAHULUAN}

Teknologi komputer dan sistem informasi berkembang sangat pesat. Dalam dunia bisnis, teknologi komputer dan sistem informasi menjadi penting untuk meningkatkan efesiensi proses. Industri trasportasi, adalah salah satu yang memanfaatkan sistem informasi untuk pengolahan data yang lebih mudah dan cepat, sehingga dapat meningkatkan pelayanan terhadap pelanggan perusahaan.

PT. Qyta Trans Group memiliki 2 bisnis utama dibidang transportasi yaitu rental dan travel. Travel yaitu mobil menjemput pelanggan kemudian mengantar sampai ke tempat tujuan. Untuk memesan tiket mobil travel yaitu pelanggan datang sendiri ke kantor atau bisa melalui telepon untuk mengetahui jadwal, tarif dan jalur yang masih tersedia, pada saat jam keberangkatan sopir akan menjemput pelanggan yang sudah memesan tiket kemudian diantar ke tempat tujuan. Sedangkan yang dimaksud sewa yaitu mobil di sewa oleh pelanggan untuk mengantar ke tempat tujuan kemudian menunggu pelanggan

menyelesaikan kegiatannya lalu mengantar pelanggan pulang ke rumah. Untuk sewa mobil yaitu pelanggan datang sendiri ke kantor atau bisa melalui telepon untuk mengetahui tarif, dan armada yang akan digunakan, kemudian sopir akan menjemput dan mengantar pelanggan sampai tempat tujuan dan mengantar kembali pulang ke rumah. Tempat tujuan ditentukan oleh pelanggan, khusus untuk tempat tujuan PT. Qyta Trans Group hanya menerima daerah yang masih lingkup pulau jawa.

Reservasi merupakan proses perjanjian berupa pemesanan sebuah produk baik barang maupun jasa yang telah terdapat suatu kesepahaman antara konsumen dengan produsen tentang produk tersebut namun belum sampai pada sebuah transaksi jual beli. Pada saat reservasi berlangsung biasanya ditandai dengan adanya proses tukar-menukar informasi antara konsumen dan produsen agar kesepahaman mengenai produk dapat terwujud (Pamudji, 2009).

PT. Qyta Trans Group sudah mempunyai sistem sendiri untuk reservasi tiket, tetapi sistem tersebut hanya bisa di akses oleh customer service, apabila ada pelanggan yang reservasi maka customer service yang meng-input data ke dalam sistem.

Berdasarkan survei Asosiasi Penyelenggara Jasa Internet Indonesia (APJII), pengguna internet di Indonesia mencapai 143,26 juta jiwa dari total Populasi penduduk Indonesia 262 juta orang. Pulau Jawa merupakan jumlah pengguna internet terbanyak dengan persentase $58,08 \%$ dari total seluruh Indonesia dan 50,08\% nya mengakses internet melalui perangkat smartphone (APJII, 2017)

Smartphone merupakan telepon yang fungsi nya menyerupai komputer, yang memiliki fasilitas kamera, email dan organizer Global Positioning System (GPS). Fitur penting yang membedakan smartphone dengan ponsel biasa adalah aplikasi untuk meningkatkan pemrosesan data dan konektivitas. (Becker, 2013). Jenis - jenis smartphone berdasarkan sistem operasi diantaranya ios apple, windows phone dan Android. Berdasarkan laporan StatCounter GlobalStats pada bulan Februari 2015 sampai dengan Februari 2016, Android merupakan sistem operasi yang mendominasi peredaran smartphone di Indonesia dengan pembagian pasar sebesar 63,34\%. (StatCounter GlobalStats, 2018).

Android merupakan sistem operasi berbasis linux yang dibuat untuk perangkat seluler layar sentuh seperti telepon pintar dan tablet. Android awalnya dikembangkan oleh Android Inc dengan dukungan finansial dari Google, yang kemudian membelinya pada tahun 2005. Sistem operasi ini dirilis resmi pada tahun 2007. Android adalah sistem operasi open source dan Google merilis kodenya di bawah lisensi Apache. Kode open source dan lisensi perizinan pada Android memungkinkan perangkat lunak untuk dimodifikasi secara bebas dan didistribusikan oleh para pembuat perangkat, operator nirkabel dan pengembang aplikasi (Agung, 2015).

Penelitian mengenai reservasi pernah dilakukan oleh Bemile, Achamong \& Danguah (2014). Penelitian ini bertujuan untuk membuat reservasi hotel secara online pada hotel Dansoman. Hansonic hotel. Konsumen tidak harus mendatangi hotel untuk melakukan pemesanan, cukup melakukan reservasi online, Konsumen juga mendapatkan informasi gambaran hotel yang akan di sewa.

Pengembangan perangkat lunak yang akan

digunakan yaitu dengan metode Extreme Programming. Metode Extreme Programming memberikan kesempatan kepada pengembang untuk merubah proses ketika sistem sedang dikerjakan (Pressman, 2010). Tidak menutup kemungkinan dalam mengerjakan sistem reservasi berbasis Android pada PT. Qyta Trans akan terjadi perubahan - perubahan agar sistem bisa sesuai dengan kebutuhan, disamping itu metode ini cocok untuk desain dan program yang berbasis object oriented yang akan digunakan untuk membangun aplikasi (Alliance, 2001).

\section{METODE PENELITIAN}

Agar penelitian yang dilakukan dan dapat terukur maka metode pengembangan sistem dapat mengakomodasi penliti dalam melakukan penelitian bertahap. Pada penelitian ini digunakan metode Extreme Programming (XP) yang merupakan salah satu metode yang tergolong kedalam Agile Methodology yang menggunakan permodelan Unified Modeling Language (UML) atau disebut juga permodelan visual. Menurut Pressman (2010) Extreme Programming didasarkan pada nilai - nilai berikut: 
a. Komunikasi

Untuk mencapai komunikasi yang efektif seharusnya terjadi antara perekayasa perangkat lunak dan para stakeholder lainnya (contoh: untuk membangun fitur - fitur dan fungsi - fungsi tertentu yang dibutuhkan bagi perangkat lunak). XP menekankan kolaborasi informal (namun bersifat lisan) antara pelanggan dan pengembang perangkat lunak, menekankan pentingnya pembentukan metafora-metafora yang efektif untuk mengomunikasikan konsep - konsep yang penting, menekankan pentingnya adaptasi terhadap umpan balik yang berkesinambungan, dan menekankan pentingnya dokumentasi yang produktif sebagai suatu media komunikasi.

b. Kesederhanaan

Untuk mencapai kesederhanaan, XP membatasi pengembang perangkat lunak melakukan perancangan hanya untuk kebutuhan - kebutuhan yang sifatnya mendesak alih - alih melakukan perancangan kebutuhan - kebutuhan yang diperlukan di masa depan. Tujuannya adalah untuk menciptakan rancangan yang sederhana yang dapat dengan mudah diimplementasikan dalam bentuk kode - kode program secara cepat. Jika rancangan tersebut selanjutnya harus ditingkatkan, rancangan yang bersangkutan dapat di refaktorisasi di waktu yang lain.

c. Umpan Balik

Umpan balik berasal dari tiga sumber: dari perangkat lunak yang diimplementasikan sendiri oleh si penulis perangkat lunak, dari para pelanggan, dan dari anggota tim perangkat lunak lain. Dengan melakukan perancangan dan kemudian menerapkan suatu strategi pengujian yang efektif, perangkat lunak (melalui langkah - langka pengujian) menyediakan bagi tim cepat umpan - umpan balik yang sangat bermanfaat. XP menggunakan unit pengujian sebagai taktik pengujian utama. Ketika masing - masing kelas dikembangkan, tim cepat mengembangkan suatu unit pengujian untuk menjalankan masing - masing operasi sesuai dengan fungsi yang berbeda - beda. Ketika suatu peningkatan dihantarkan ke pelanggan, user stories atau use cases yang diimplementasikan sebagai hasil pengingkatan digunakan sebagai dasar untuk tes penerimaan. Tingkat dimana perangkat lunak menerapkan keluaran (output), fungsi, dan perilaku dari use case pada dasarnya (bagi tim cepat) merupakan suatu bentuk umpan balik yang sangat bermanfaat. Akhirnya, ketika kebutuhan - kebutuhan baru yang diperoleh sebagai bagian dari perancangan iteratif muncul, tim cepat menyediakan bagi pelanggan suatu umpan balik yang cepat mengenai dampak biaya dan jadwal atas kebutuhan - kebutuhan yang baru tersebut.

\section{d. Keberanian}

Kepatuhan ketat terhadap praktik - praktik XP tertentu menuntut keberanian. Sebuah istilah yang lebih tepat digunakan adalah disiplin. Misalnya, sering kali ada tekanan signifikan untuk melakukan perancangan demi kebutuhan di masa depan. Sebagian besar tim perangkat lunak cepat mengalah kemudian berdebat bahwa "melakukan perancangan untuk hari esok" akan menghemat waktu dan tenaga dalam jangka panjang. Sebuah tim XP yang cepat harus memiliki disiplin (keberanian) untuk melakukan perancangan hanya untuk saat ini dan mengakui bahwa kebutuhan - kebutuhan di masa depan dapat berubah secara drastis, sehingga menuntut pengerjaan ulang yang substansial atas rancangan - rancangan yang telah dibuat serta menuntut pengerjaan ulang yang substansial pula atas kode - kode program komputer yang telah diimplementasikan.

e. Rasa Hormat

Dengan mengikuti masing - masing nilai penting tersebut, tim cepat menanamkan rasa hormat diantara para anggota tim perangkat lunak, diantara stakeholder lainnya dan anggota perangkat lunak, dan secara tidak langsung menanamkan rasa hormat untuk perangkat lunak itu sendiri. Ketika mereka berhasil mencapai penghantaran peningkatan perangkat lunak pada para pelanggan secara tepat waktu, tim cepat mengembangkan rasa hormat yang tumbuh pada proses XP.

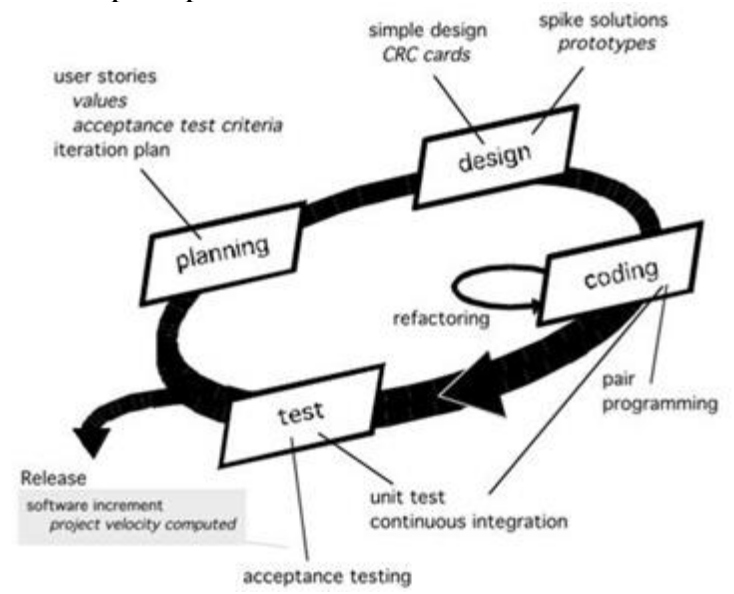

Gambar 1. Skema Extreme Programming

(Sumber: Pressman, 2005)

Adapun proses dan tahapan Extreme Programming yaitu:

1. Perencanaan

Kegiatan perencanaan (disebut juga planning game) biasanya dimulai dengan mendengarkan suatu kegiatan yang bertujuan untuk mengumpulkan kebutuhan - kebutuhan yang memungkinkan anggota teknis tim XP memahami konteks bisnis untuk perangkat lunak yang akan dikembangkan dan untuk merasakan perlunya keluaran - keluaran (output), fitur - fitur utama, dan fungsionalitas. Aktivitas aktivitas mendengarkan pada dasarnya mengarah kepada pembuatan serangkaian "cerita" (juga disebut user stories) yang menggambarkan keluaran yang diperlukan, fitur - fitur, dan fungsionalitas fungsionalitas yang akan dibangun menggunakan perangkat lunak yang akan dikembangkan. Setiap 
cerita umumnya ditulis oleh para pelanggan dan diletakkan pada kartu indeks. Pelanggan - pelanggan memberikan suatu nilai (yaitu, suatu prioritas) pada cerita - cerita tertentu berdasarkan seluruh nilai bisnis dari fitur atau fungsi. Anggota tim XP kemudian menilai setiap cerita dan mentapkan biayanya yang diukur dalam bentuk minggu - minggu yang diperlukan untuk melakukan pengembangan cerita tersebut. Jika cerita ini diperkirakan membutuhkan lebih dari tiga minggu pengembangan, pelanggan akan diminta untuk membagi cerita tersebut kedalam cerita - cerita kecil dan perhitungan - perhitungan nilai dan biaya terjadi lagi. Penting untuk diperhatikan bahwa cerita baru dapat ditulis setiap saat.

2. Perancangan

Perancangan XP dengan ketat mengikuti prinsip "tetap sederhana". Sebuah hasil perancangan yang sederhana selalu lebih disukai daripada GambaranGambaran yang lebih kompleks. Selain itu, perancangan XP akan memberikan panduan implementasi untuk suatu cerita ketika cerita itu ditulis, tidak kurang, tidak lebih. Rancanganrancangan dan fungsionalitas-funsionalitas tambahan (karena pengembang menganggap nantinya akan diperlukan) tidak terlalu disarankan.

3. Pengkodean

Setelah cerita dikembangkan dan karya rancangan awal dilakukan, tim perangkat lunak cepat XP tidak langsung beralih ke kode - kode program, tetapi lebih dulu akan mengembangkan serangkaian unit pengujian yang akan menjalankan setiap cerita yang akan disertakan pada rilis yang ada (peningkatan perangkat lunak). Setelah unit pengujian dibuat, pengembang perangkat lunak akan lebih mampu berkonsentrasi pada apa yang harus diimplementasikan supaya lulus dari unit pengujian tersebut. Tidak ada yang di tambahkan (tetap sederhana). Ketika kode - kode program telah selesai dituliskan, kode - kode program tersebut dapat langsung di uji menggunkan unit pengujian yang telah dirancang sebelumnya, sehingga bisa langsung memberikan umpan balik kepada para pengembang.

\section{Pengujian}

Pembuatan unit pengujian sebelum pengkodean dimulai merupakan elemen kunci dari pendekatan pengembangan perangkat lunak cepat XP. Unit pengujian yang harus dibuat dan kemudian dijalankan menggunakan kerangka kerja yang memungkinkan mereka untuk diotomatisasi (sehingga mereka dapat dijalankan dengan mudah dapat dijalankan berulang kali).

\section{HASIL DAN PEMBAHASAN}

Metode pengembangan sistem yang digunakan adalah model Extreme Programming yang terdiri dari 4 tahapan, yaitu perencanaan, perancangan, pengkodean dan pengujian. Berikut merupakan tahapan yang telah dilakukan dalam pembuatan sistem reservasi berbasis Android pada PT. Qyta Trans Group :

\section{Perencanaan}

Pada bagian perencanaan dilakukan analisa kebutuhan untuk membangun sistem reservasi. Analisa kebutuhan fungsional merupakan paparan mengenai fitur - fitur yang ada dalam sistem. Analisa kebutuhan fungsional ini nantinya akan memberikan gambaran mengenai fungsi - fungsi yang ada pada sistem sesuai dengan kebutuhan pengguna. Analisa kebutuhan fungsional sebagai berikut:

1) Admin
a) Pengolahan data armada.
b) Pengolahan data customer.
c) Pengolahan data jabatan.
d) Pengolahan data jadwal.
e) Pengolahan data kantor.
f) Pengolahan data karyawan.
g) Pengolahan data reservasi.
h) Pengolahan data rute.
i) Pengolahan data wilayah.

2) Pengguna
a) Form login.
b) Form membuat akun.
c) Tampilan proses reservasi travel.
d) Tampilan proses sewa armada.
e) Tampilan profil pengguna.
f) Tampilan tentang sistem reservasi.
g) Tampilan riwayat reservasi.
h) Tampilan detail riwayat reservasi.

\section{Perancangan}

Untuk perancangan sistem dalam penelitian ini menggunakan bahasa pemodelan Unified Modelling Language (UML) yang menjadi standar untuk visualisasi, perancangan, serta pendokumentasian sebuat software atau sistem yang bersifat object oriented. Perancangan sistem reservasi meliputi:

a. Use Case Diagram

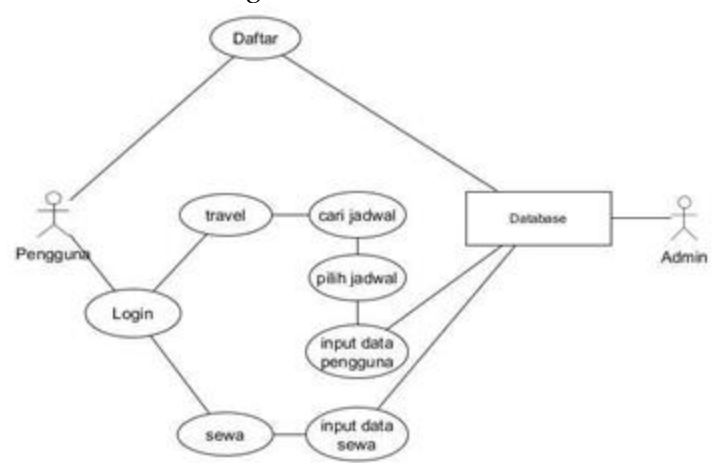

Gambar 2. Use Case Diagram

Gambar 2. menjelaskan interaksi antara aktor dan sistem reservasi. Aktor pertama yaitu pengguna yang berinteraksi dengan sistem untuk daftar akun, 
reservasi tiket travel, reservasi sewa armada dan cek semua riwayat transaksi. Sedangkan aktor yang kedua yaitu admin yang mengelola proses reservasi travel dan mengelola proses reservasi sewa armada.

\section{b. Activity Diagram}

Diagram aktivitas atau Activity Diagram menggambarkan aktivitas dari sebuah sistem. Berikut Gambaran Activity diagram dari sistem reservasi berbasis Android pada PT. Qyta Trans Group:

1) Mengakases halaman pertama

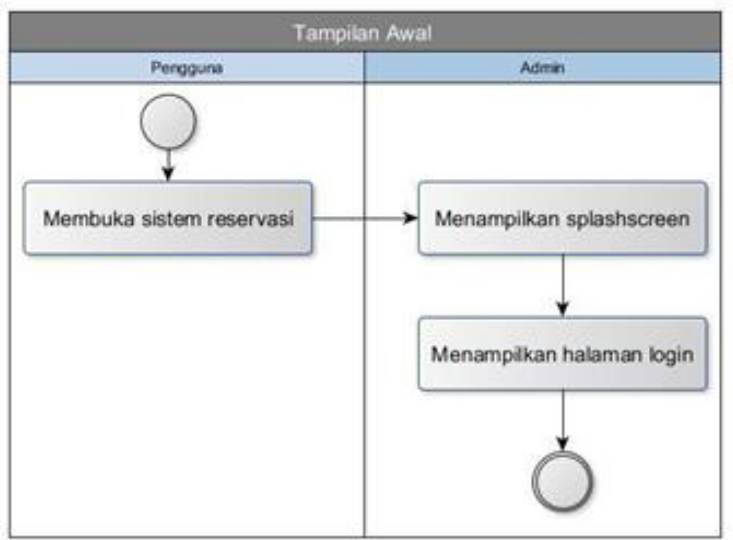

Gambar 3. Activity Tampilan Awal

Ketika pengguna membuka sistem reservasi saat pertama kali maka tampilan yang pertama kali muncul adalah splashscreen berupa logo PT. Qyta Trans Group dan Gambar loading sistem, kemudian muncul tampilan login setelah tampilan splashscreen selesai.

2) Mengakses halaman login

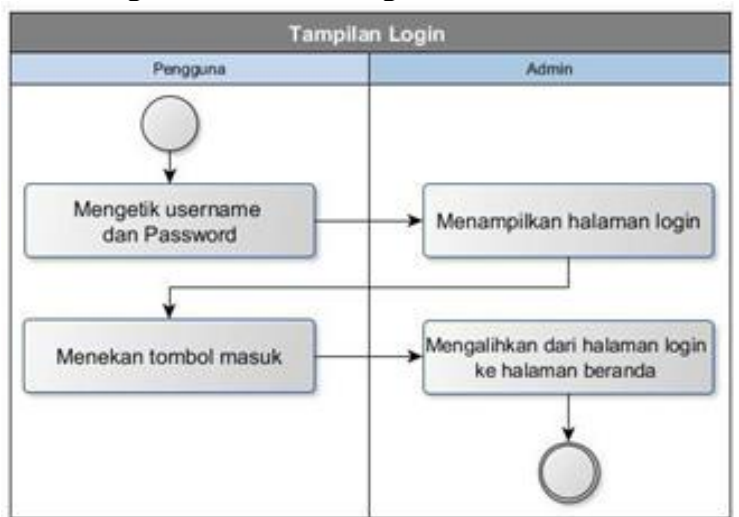

Gambar 4. Activity Tampilan Login

Setalah masuk di tampilan login, pengguna harus mengisi formulir username dan password, kemudian pengguna menekan tombol masuk untuk melanjutkan. Setelah pengguna menekan tombol masuk maka sistem akan mengalihkan dari halaman login ke halaman beranda.

3) Mengakses halaman daftar

Ketika pengguna belum punya akun untuk masuk ke sistem reservasi, maka pengguna harus daftar terlebih dahulu yaitu dengan masuk ke halaman daftar, caranya dengan menekan tombol daftar yang ada di halaman login, selanjutnya sistem akan mengalihkan dari halaman login ke halaman daftar,

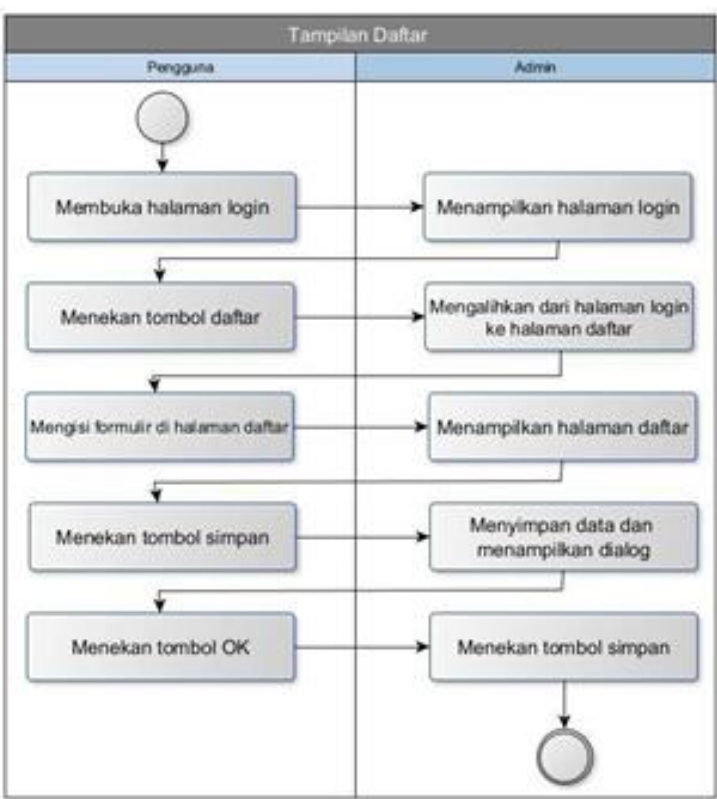

Gambar 5. Activity Tampilan Daftar setelah di halaman daftar pengguna harus mengisi semua formulir yang tersedia. Setelah mengisi formulir, pengguna menekan tombol simpan untuk melanjutkan, kemudian sistem menyimpan data pengguna dan menampilkan popup pemberitahuan data sudah tersimpan, kemudian pengguna harus menekan tombol ok untuk melanjutkan. Setelah pengguna menekan tombol ok, sistem langsung mengalihkan ke halaman login.

4) Mengakses halaman profil

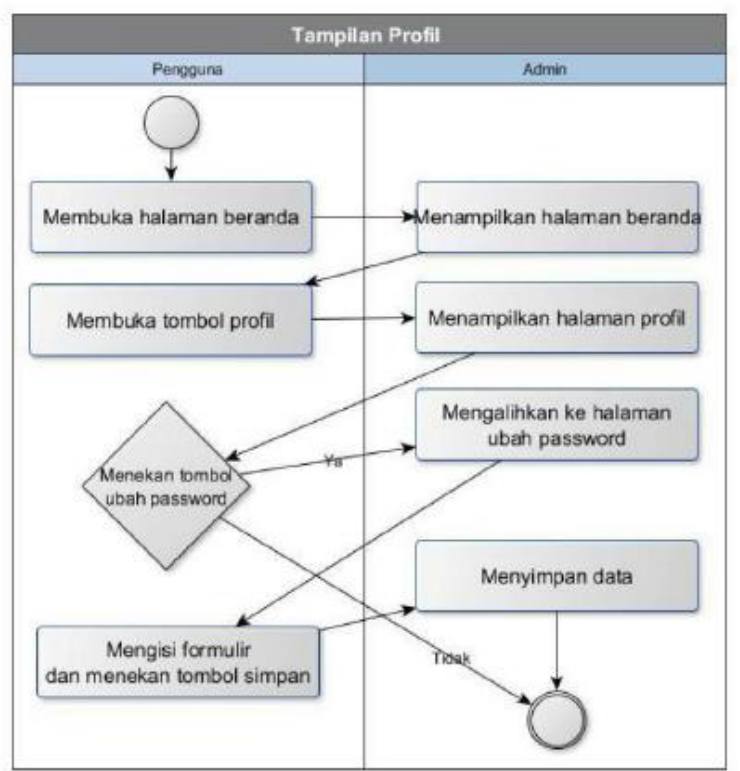

Gambar 6. Activity Tampilan Profil

Setelah pengguna berhasil login, halaman selanjutnya adalah halaman beranda. Pada halaman beranda pilih menu profil, kemudian sistem mengalihkan ke halaman profil. Halaman profil menampilkan data dari pengguna, selain itu terdapat tombol ubah password, kalau pengguna ingin mengubah password bisa menekan tombol ubah password, setalah itu sistem akan mengalihkan ke 
tampilan ubah password. Pada tampilan ubah password, pengguna harus mengisi password lama dan password baru, kemudian tekan tombol simpan, selanjutnya sistem akan menyimpan data password baru dan langsung mengalihkan ke halaman beranda.

5) Mengakses halaman tentang

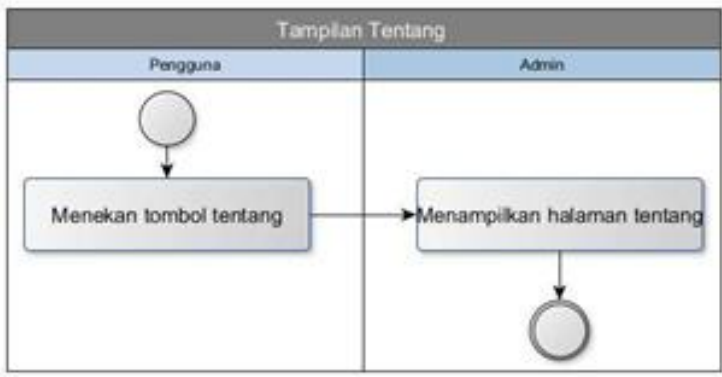

Gambar 7. Activity Tampilan Tentang

Setelah pengguna masuk ke halaman beranda, pilih menu tentang, kemudian sistem mengalihkan ke halaman tentang. Pada halaman tentang terdapat keterangan tentang sistem reservasi mengenai versi dan cara penggunaan.

6) Mengakses halaman travel

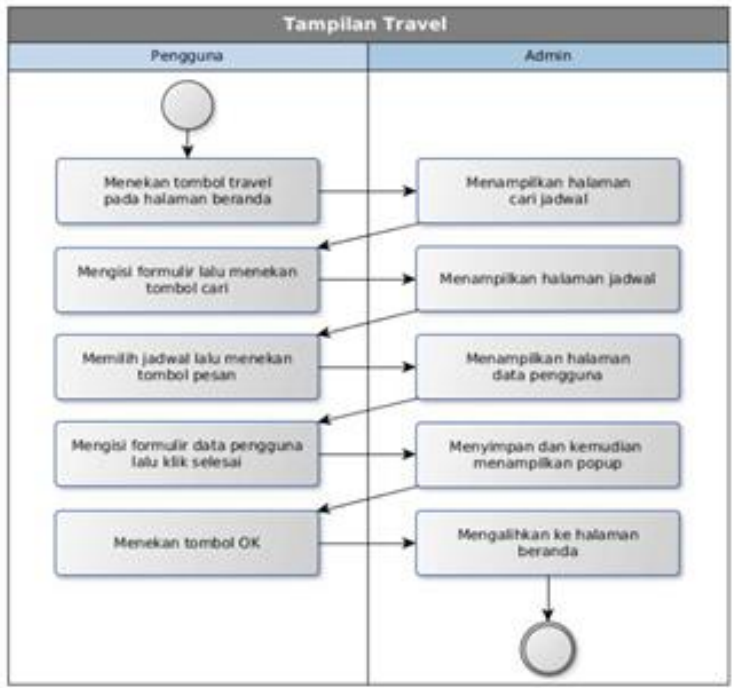

Gambar 8. Activity Tampilan Travel

Setelah pengguna masuk halaman beranda, pilih menu travel, kemudian sistem mengalihkan ke halaman cari jadwal. Pada halaman cari jadwal pengguna harus mengisi formulir keberangakatan, tujuan dan tanggal jadwal, setelah itu tekan tombol cari, selanjutnya sistem akan mengalihkan ke halaman jadwal. Pada halaman jadwal terdapat jadwal yang tersedia sesuai yang dicari, kemudian pilih salah satu jadwal dengan menekan tombol pesan, selanjutnya sistem akan mengalihkan ke halaman data pengguna. Pada halaman data pengguna, pengguna harus mengisi semua formulir, kemudian tekan tombol selesai setelah selesai mengisi semua formulir, selnajutnya sistema akan menyimpan data dan menampilkan popup untuk memberitahu pengguna bahwa datanya sudah tersimpan, kemudian pengguna tekan ok pada pop-up lalu sistem langsung mengahlihkan ke halaman beranda.
7) Mengakses halaman sewa

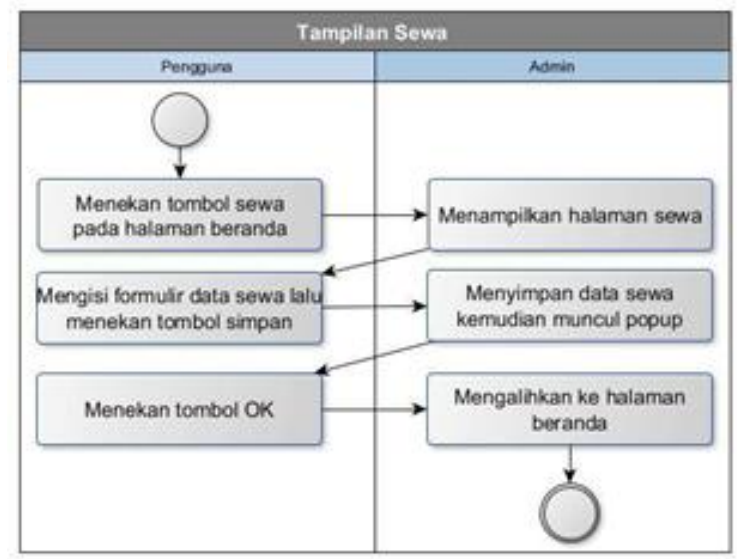

Gambar 9. Activity Tampilan Sewa

Setelah pengguna masuk ke halaman beranda, pilih menu sewa, kemudian sistem akan mengalihkan ke halaman data pengguna sewa armada. Pada halaman data pengguna, pengguna harus mengisi semua formulir yang tersedia, setelah tekan tombol simpan untuk melanjutkan, kemudian sistem menyimpan data dan menampilkan pop-up untuk memberitahukan pengguna bahwa data sudah tersimpan, kemudian pengguna tekan ok, lalu sistem mengalihkan ke halaman beranda.

c. Sequence Diagram

Sequence diagram menggambarkan tingkah laku objek pada use case dengan mendeskripsikan waktu hidup objek dan pesan yang di kirimkan dan diterima antar objek.

1) Sequence diagram mengakses halaman login, daftar dan beranda

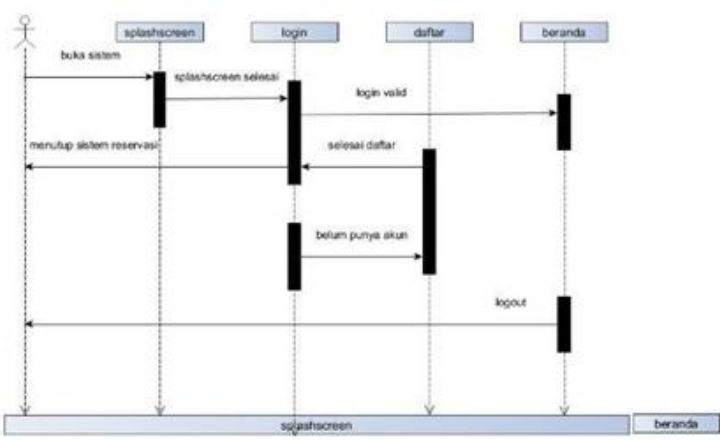

Gambar 10. Sequence diagram Login, Daftar dan Beranda

2) Sequence diagram mengakses halaman profil dan tentang

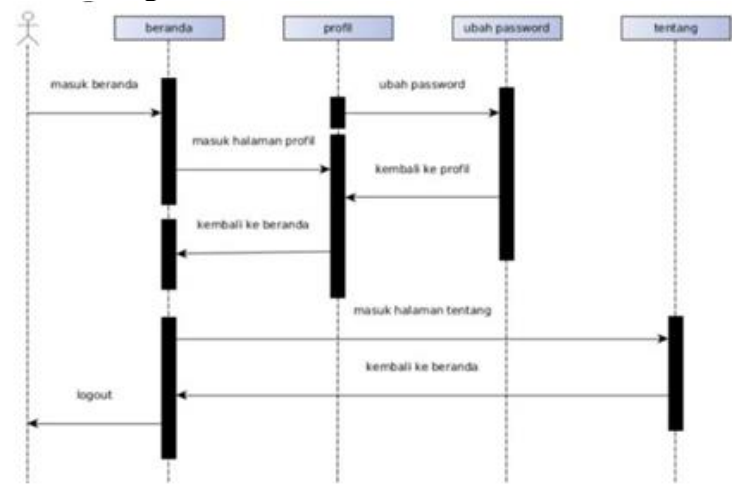

Gambar 12. Sequence diagram profil dan tentang 
3) Sequence diagram mengakses halaman travel

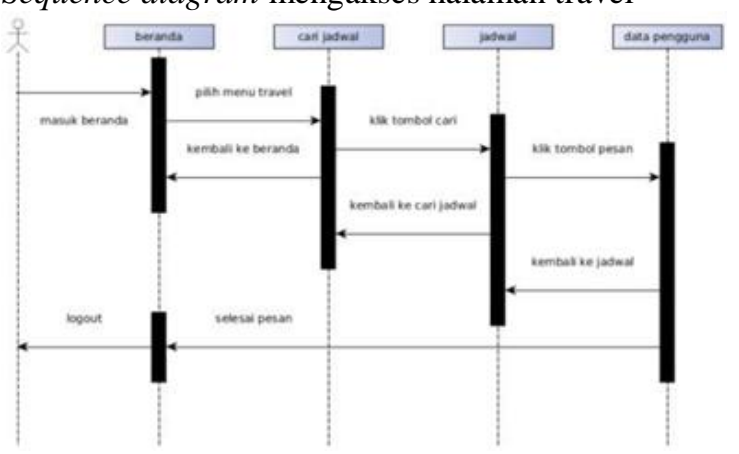

Gambar 13 Sequence diagram travel

4) Sequence diagram mengakses halaman sewa

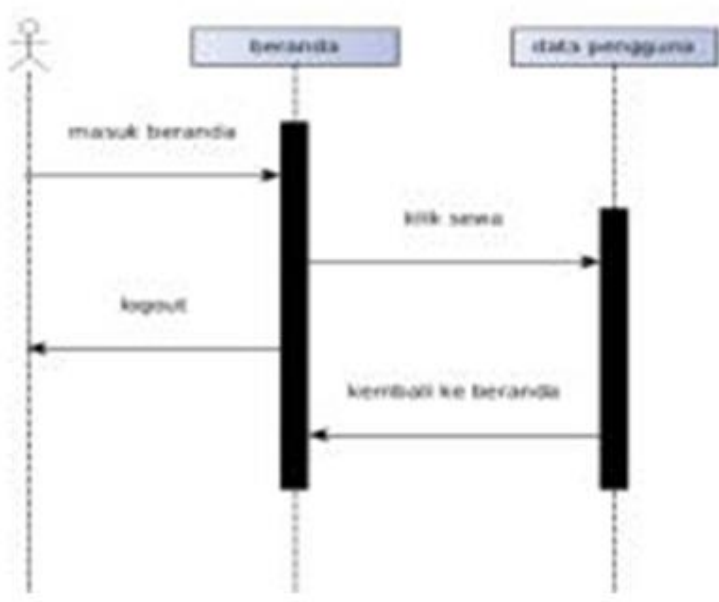

Gambar 14. Sequence diagram Sewa

\section{Pengkodingan}

Pengkodean yang digunakan dalam membangun sistem ini adalah bahasa pemrograman Java, kemudian untuk editor bahasa pemrograman Java menggunakan Android Studio versi 3. Berikut penjelasan beberapa kode inti yang ada pada sistem reservasi berbasis Android pada PT. Qyta Trans Group yaitu bagian kode program "travel" dan kode program "sewa":

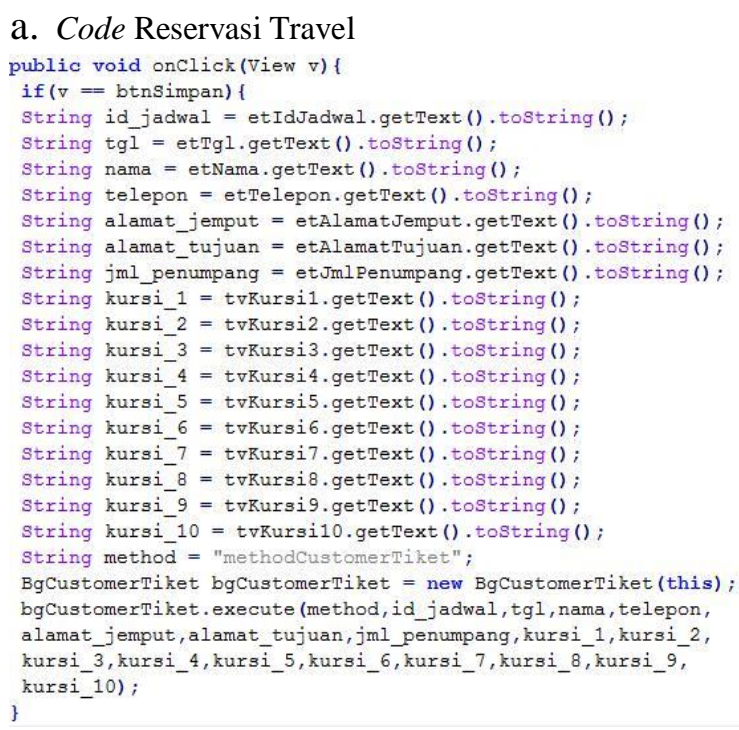

Gambar 15. Code Reservasi Travel
Kode diatas adalah kode untuk membuat proses menyimpan data pelanggan untuk reservasi travel, data yang disimpan terdiri dari jadwal, tanggal pesan, nama, telepon, alamat jemput, alamat tujuan jumlah penumpang dan kursi yang dipilih.

\section{b. Code Reservasi Sewa}

btnpesan, setonclicktistener (new View, OnclickListener () goverride

public void onclick (Viex viex) !

String nats = etNama.getText ().tosering () ;

string telepon = etTelepon.getText ().tostring ();

string ktp = etktp, qetText (), tostring (),

string tujuan - etTujuan.getText () .tostring (),

string tarif - tvTarifHidden.getFext () - tostring ();

String dtberangkattgl - berangkattgl;

string dtberangkatjan - berangkatjan;

string dtpulangtgl - pulangtgl;

string dtpulangjam = pulangjam;

string dtjenisarmada - jenisarmada;

string dtjmlarmada - jmlarmada;

sering method = "mothodgers";

BgSewa bgsewa - new BgSewa (DataCustconerSewa. this); bgsewa , execute (method, nama, telepon, ktp, tujuan, tarif, dtberangkattgl, dtberangkatjam, dtpulangtgl, dtpulangjan, dt jenisarmada, dtjmlarmada); 1

) :

Gambar 17. Tampilan Code Reservasi Sewa

Kode diatas adalah kode untuk membuat proses menyimpan data pelanggan untuk reservasi sewa, data yang disimpan terdiri nama, telepon, nomor ktp, tujuan, tarif, tanggal berangkat, tanggal pulang, jenis armada dan jumlah armda.

d. User Interface Sistem Reservasi Aplikasi Andorid 1) Tampilan splashscreen

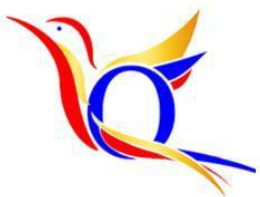

\section{Gambar 15. Splashscreen}

Gambar 15. Tampilan splashscreen adalah tampilan pertama kali ketika sistem reservasi di buka dan terdapat animasi pada logo selama 4 detik.

2) Tampilan Register

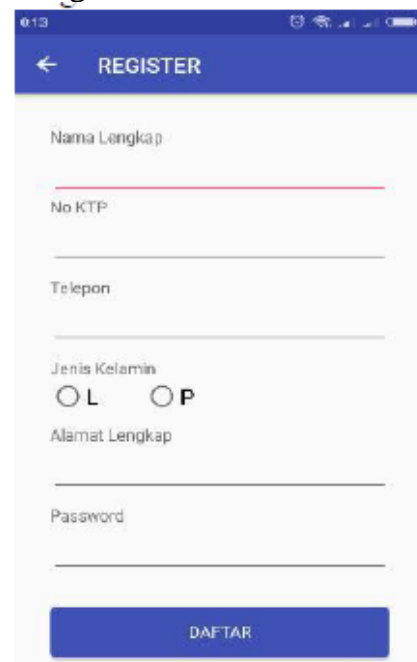

Gambar 16.Tampilan Register 
Pada tampilan register terdapat formulir nama lengkap, nomor KTP, telepon, jenis kelamin, alamat lengkap dan password. Semua formulir harus diisi semua dan setelah diisi semua tekan tombol register untuk melanjutkan.

3) Tampilan Beranda

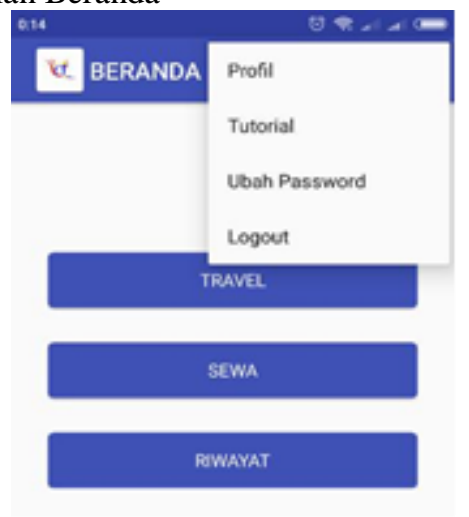

Gambar 17. Tampilan Beranda

Pada tampilan beranda terdapat menu utama dan menu toolbar. Menu utama yaitu travel, sewa dan riwayat sedangkan menu toolbar yaitu profil, tutorial, ubah password dan logout.

4) Tampilan Cari Jadwal Sewa

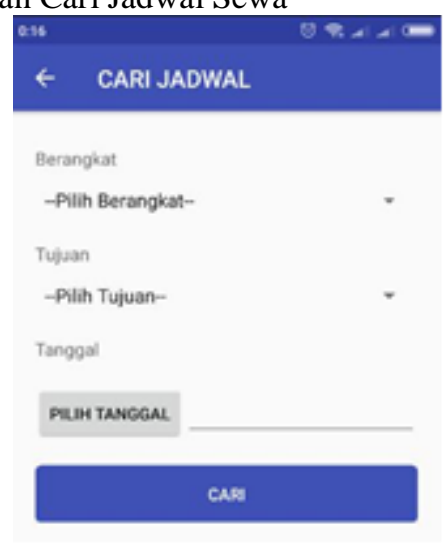

Gambar 18. Tampilan Cari Jadwal Sewa

Pada tampilan cari jadwal terdapat formulir berangkat, tujuan dan tanggal. Jika sudah diisi semua kemudian klik tombol cari untuk mencari jadwal yang tersedia.

5) Tampilan Jadwal

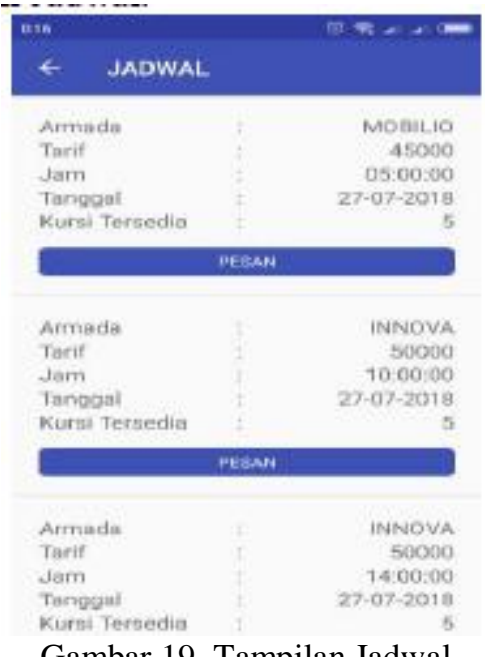

Gambar 19. Tampilan Jadwal
Pada tampilan jadwal terdapat keterangan nama armada, tarif atau harga, jam keberangkatan, tanggal keberangkatan dan kursi yang tersedia. Jika sudah menentukan jadwal selanjutnya klik pesan.

6) Tampilan Data Customer Travel

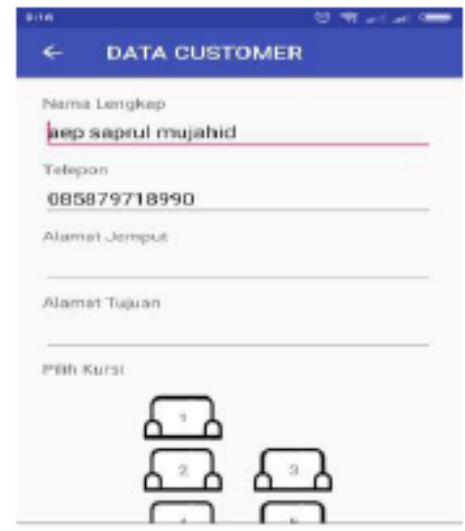

Gambar 20. Tampilan Data Costumer Travel

Data customer travel adalah tampilan terakhir untuk reservasi travel, disini terdapat formulir nama lengkap dan telepon yang sudah terisi otomatis dan formulir lainnya yang harus diisi yaitu alamat jemput, alamat tujuan dan kursi yang tersedia. Jika sudah terisi semua lalu klik pesan untuk reservasi.

7) Tampilan Jadwal Sewa

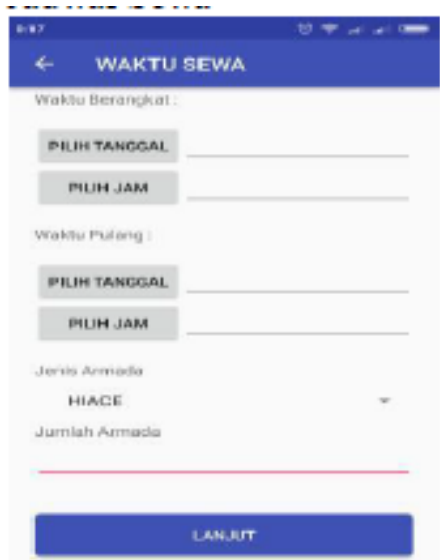

Gambar 21. Tampilan Jadwal Sewa

Pada tampilan waktu sewa terdapat formulir waktu berangkat, waktu pulang, jenis armada dan jumlah armada. Waktu berangkat dan waktu pulang terdiri dari formulir tanggal dan jam. Jika semuanya sudah terisi selanjutnya tekan tombol lanjut untuk melanjutkan.

8) Tampilan Data Customer Sewa

Tampilan data customer sewa adalah tampilan terakhir untuk reservasi sewa, disini terdapat formulir nama lengkap, nomor telepon, nomor KTP, tujuan dan tarif. Pengguna hanya tinggal mengisi formulir tujuan saja, karena formulir yang lain sudah terisi otomatis, tekan tombol pesan untuk reservasi. 


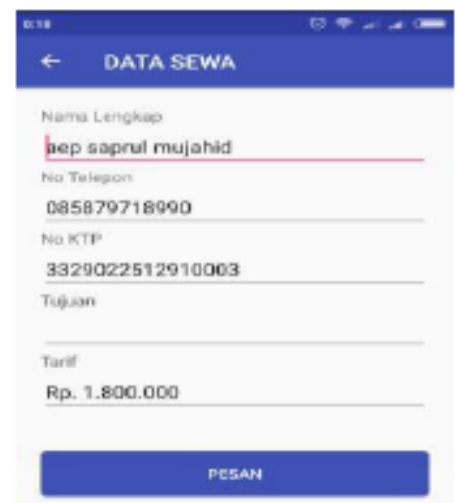

Gambar 22. Tampilan Data Customer Sewa 9) Tampilan Riwayat

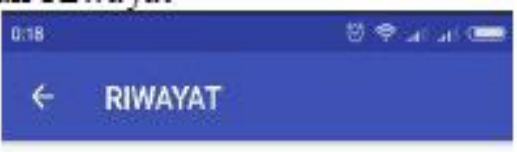

GWAYAT RESERVASI TRAVEL.

RIWAYAT RESERVASISEWA

Gambar 23. Tampilan Riwayat

Pada tampilan riwayat terdapat tombol riwayat reservasi travel dan riwayat reservasi sewa. Tombol riwayat reservasi travel untuk melihat riwayat reservasi travel yang pernah dilakukan pengguna dan tombol riwayat reservasi sewa untuk melihat riwayat reservasi sewa armada yang pernah dilakukan.

10) Tampilan Login (Admin)

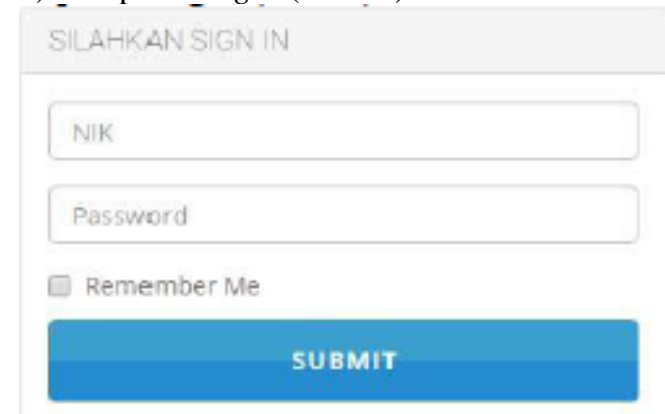

Gambar 24. Tampilan Login (admin)

Untuk masuk ke halaman admin user harus login terlebih dahulu melalui URL: http://qytatiket.com/admine/. Pada tampilan login user harus memasukkan Nomor Induk Karyawan (NIK) dan password yang sudah diberikan dari perusahaan.

11) Tampilan Menu Beranda (Admin)

Ketika user berhasil login maka tampilan awal halaman admin adalah beranda, pada halaman beranda berisi informasi jumlah armada, jumlah customer, jumlah kantor, jumlah karyawan, jumlah

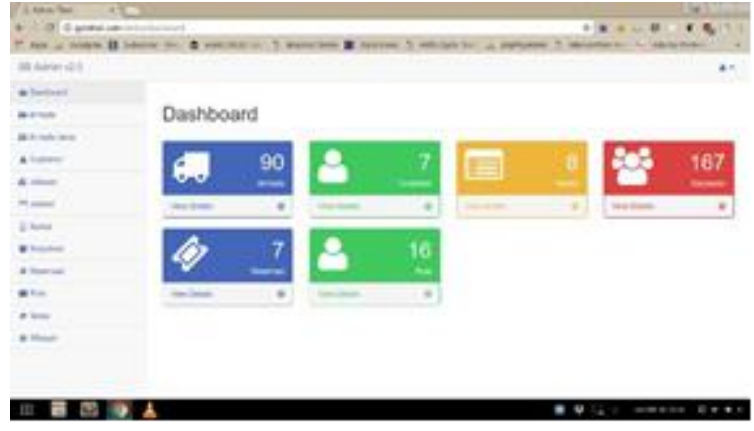

Gambar 25. Tampilan Menu Beranda (Admin) reservasi dan jumlah rute. Admin dapat meng klik masing-masing menu untuk melakukan pengelolaan.

\section{Pengujian}

Pengujian dilakukan untuk memastikan sistem bisa berfungsi dengan baik, pada tahap pengujian akan dilakukan dengan 2 pendekatan yaitu Alpha Testing (Black-box) dan pengujian beta (kuesioner) (Wahyudi, Utami \& Arief, 2016).

\section{a. Pengujian Black-box}

Pengujian Black-box berdasarkan fungsi sistem yang dilakukan pengembang untuk mencari kesalahan atau error pada saat sistem dijalankan, sehingga apabila terdapat error bisa langsung diperbaiki. Aplikasi reservasi Android dapat dijalankan minimal pada Android versi Ice Cream Sandwich (ICS).

b. Pengujian Kuesioner

Pengujian ini dilakukan terhadap pengguna sistem dengan mengisi kuesioner untuk menilai sistem reservasi berbasis Android pada PT. Qyta Trans Group. Pengujian dilakukan dengan menjalankan sistem reservasi secara keseluruhan, kemudian responden diberikan lembaran pertanyaan mengenai sistem reservasi dan responden menjawab dengan memberikan tanda centang pada kolom yang tersedia. Pengujiian kuesioner (Lutfi \& Wahyudi, 2017).

1) Daftar Pertanyaan

\begin{tabular}{ll}
\multicolumn{1}{c}{ Tabel 2. Dimensi dan Variabel instrumen } \\
\hline \multicolumn{1}{c}{ Dimensi } & \multicolumn{1}{c}{ Pertanyaan } \\
\hline Kegunaan & 1. Kemudahan untuk dioperasikan \\
(Usability) & $\begin{array}{l}\text { 2. Kemudahan untuk navigasi } \\
\text { 3. Tampilan yang atraktif } \\
\text { 4. Menyediakan informasi yang mudah }\end{array}$ \\
Kualitas & dibaca dan dipahami \\
Informasi & 5. Menyediakan informasi yang cukup detail \\
(Information & 6. Menyediakan informasi yang akurat \\
Quality) & 7. Menyajikan informasi dalam format yang \\
Kualitas Interaksi & 8 Menyediakan keamanan untuk melengkapi \\
Pelayanan & transaksi \\
(Service & Kemudahan untuk menarik minat dan \\
Interaction & perhatian \\
$\begin{array}{l}\text { Quality) } \\
\text { Keseluruhan } \\
\text { (Overall }\end{array}$ & Tampilan aplikasi secara keseluruhan \\
Impression) & 10baik
\end{tabular}


Tabel 1. Tabel Pengujian Black-box Terhadap Aplikasi Android

\begin{tabular}{cllll}
\hline No & \multicolumn{1}{c}{ Layout } & \multicolumn{1}{c}{ Aksi } & \multicolumn{1}{c}{ Hasil } & Status \\
\hline 1 & Splash & Membuka sistem pertama & Muncul tampilan logo PT. Qyta & Sukses \\
& screen & kali & Trans Group & Sukses \\
2 & Dashboard & Tekan tombol login & Pindah ke halaman login & Sukses \\
3 & Dashboard & Tekan tombol daftar & Pindah ke halaman daftar & Sukses \\
4 & Login & Mengisi form username & Apabila username dan password & Suan \\
& & dan password lalu tekan & sesuai dengan yang ada di database & \\
& & tombol masuk & maka login berhasil & Sukses \\
6 & Daftar & Mengisi form daftar & Data berhasil disimpan & Sukses \\
7 & Beranda & Pilih menu profil & Pindah ke halaman profil & Sukses \\
8 & Beranda & Pilih menu tentang & Pindah ke halaman tentang & Sukses \\
9 & Beranda & Pilih logout & Keluar dari halaman beranda & Sukses \\
10 & Beranda & Pilih tombol travel & Pindah ke halaman cari jadwal & Sukses \\
\hline 11 & Beranda & Pilih tombol sewa & Pindah ke halaman data sewa & \\
\hline
\end{tabular}

2) Skala Jawaban

Tabel 5. Skala Jawaban

\begin{tabular}{cc}
\hline Skala Jawaban & Skor \\
\hline Sangat Setuju & 4 \\
Setuju & 3 \\
Tidak Setuju & 2 \\
Sangat Tidak Setuju & 1 \\
\hline
\end{tabular}

3) Pengambilan Sampel

Pengambilan sampel dari total populasi konsumen

PT. Qyta Trans Group, dan totalnya ada 623 orang. Untuk pengambilan sampel menggunakan rumus Slovin sebagai berikut:

$$
\mathrm{N}
$$

$$
\eta=1+N(e) 2
$$

Dimana

$\eta=$ ukuran sampel.

$\mathrm{N}=$ ukuran populasi.

e = persen kelonggaran ketidaktelitian (error tolerance).

$$
\eta=\frac{623}{623 *(0.1)^{2}}
$$

\begin{tabular}{|c|c|c|c|c|c|c|}
\hline \multirow{2}{*}{ No } & \multirow{2}{*}{ Pertanyaan } & \multicolumn{5}{|c|}{ Penilaian } \\
\hline & & SS & $\mathbf{S}$ & $\mathbf{N}$ & TS & STS \\
\hline 1 & Kemudahan untuk dioperasikan & 56 & 29 & 1 & 0 & 0 \\
\hline 2 & Kemudahan untuk navigasi & 39 & 31 & 16 & 0 & 0 \\
\hline 3 & Tampilan yang atraktif & 12 & 29 & 35 & 10 & 0 \\
\hline 4 & $\begin{array}{l}\text { Menyediakan informasi yang } \\
\text { mudah dibaca dan dipahami }\end{array}$ & 17 & 44 & 24 & 1 & 0 \\
\hline 5 & $\begin{array}{l}\text { Menyediakan informasi yang } \\
\text { cukup detail }\end{array}$ & 5 & 40 & 41 & 0 & 0 \\
\hline 6 & $\begin{array}{l}\text { Menyediakan informasi yang } \\
\text { akurat }\end{array}$ & 21 & 37 & 27 & 1 & 0 \\
\hline 7 & $\begin{array}{l}\text { Menyajikan informasi dalam } \\
\text { format yang sesuai }\end{array}$ & 14 & 61 & 11 & 0 & 0 \\
\hline & Tampilan Aplikasi secara & 14 & 65 & 7 & 0 & 0 \\
\hline
\end{tabular}

Dengan demikian jumlah sampel dalam penelitian ini adalah 86 responden.

\section{4) Perhitungan}

Setelah selesai menghitung rumus indeks tiap tiap pertanyaan, diperlukan kriteria skor berdasarkan interval (jarak), rumus interval dalam bentuk presentase sebagai berikut:

$1=100 /$ bobot nilai tertinggi

$$
1=100 / 4=25
$$

Sehingga dihasilkan interval 25, berikut skor berdasarkan interval:
1) Angka $0 \%-25 \%$
2) Angka $26 \%-50 \%$
3) Angka $51 \%-75 \%$
= sangat tidak setuju
$=$ tidak setuju
= setuju
4) Angka $76 \%-100 \%$
= sangat setuju

Tabel 7. Hasil Akhir Pengujian

\begin{tabular}{ccc}
\hline \multicolumn{3}{c}{ Tabel 7. Hasil Akhir Pengujian } \\
\hline Pertanyaan ke & Indeks & Kategori \\
\hline 1 & $85,2 \%$ & Sangat setuju \\
2 & $81,9 \%$ & Sangat setuju \\
3 & $75 \%$ & Sangat setuju \\
4 & $82,2 \%$ & Sangat setuju \\
5 & $77,3 \%$ & Sangat setuju \\
6 & $76,7 \%$ & Sangat setuju \\
7 & $79,6 \%$ & Sangat setuju \\
8 & $80,2 \%$ & Sangat setuju \\
9 & $76,4 \%$ & Sangat setuju \\
10 & $77 \%$ & Sangat setuju \\
\hline & & 77 ar
\end{tabular}
pengujian rata - rata rumus indeks sebagai berikut: $(85,2 \%+81,9 \%+75 \%+82,2 \%+77,3 \%+76,7$ $\%+79,6 \%+80,2 \%+76,4 \%+77 \%) / 10=79,15 \%$

Jadi rata - rata rumus indeks dari responden sebesar 79,15\% termasuk dalam kategori sangat setuju terhadap kepuasan sistem yang dibuat karena telah memenuhi aspek - aspek yang ada.

\section{KESIMPULAN \\ 4.1 Kesimpulan}

Sistem reservasi yang di bangun berbasis Android dan Website pada PT. Qyta Trans Group menggunakan Metode Extreme Programming sebagai alternatif reservasi tiket travel dan sewa mobil. Aplikasi Android merupakan Aplikasi yang diperuntukkan bagi konsumen dan Website diperuntukkan bagi admin yang mengelola data user dan pemesanan. Aplikasi reservasi Android dapat dijalankan minimal pada Android versi Ice Cream Sandwich (ICS). Pengujian dilakukan dengan dua pendekatan Alpha Testing dan Beta Testing. Hasil dari pengujian Alpha Testing menggunakan metode Black-box menguji fungsional sistem pada aplikasi Android yang hasilnya semua fungsi yang ada pada aplikasi Android dapat berjalan sesuai yang 
diharapkan. Sementara hasil pengujian Beta Testing terhadap aplikasi Android yang berhubungan langsung dengan konsumen PT Qyta Trans menggunakan metode kuesioner hasilnya menyatakan $79,15 \%$ persen responden setuju aplikasi sudah layak di implementasikan. Aplikasi Android untuk Reservasi dapat di download pada url: https://bit.ly/2NRsitw.

\subsection{Saran}

Menambahkan penunjuk arah menggunakan Google Maps pada saat pencarian alamat penjemputan pelanggan, agar sopir yang menjemput pelanggan memiliki panduan atau petunjuk arah dalam penjemputan pelanggan. menambahkan fitur pembayaran melalui sistem untuk memudahkan pembayaran reservasi travel ataupun sewa armada.

\section{DAFTAR PUSTAKA}

ALLIANCE AGILE. (2001). Manifesto for Agile Software Development. Diambil dari: http://www.agilemanifesto.org/

GREGORIUS AGUNG. 2015. Mengenal Dasar Dasar Pemrograman Android Yogyakarta. Elex Media Komputindo.

ASOSIASI PENYELENGGARA JASA INTERNET INDONESIA (APJII). (2017). Hasil Survei Penetrasi dan Perilaku Pengguna Internet Indonesia 2017. Diambil dari: https://apjii.or.id/survei.

ANDI. 2011. Aplikasi Web Database Dengan Dreamweaver dan PHP - MySql. Yogyakarta. Andi Offset.

BEMILE, ACHAMONG \& DANGUAH. (2014). Online Hotel Reservation System IJISET International Journal of Innovative Science, Engineering \& Technology, Vol. 1 Issue 9, November 2014.

EDWIN B. FLIPPO. 2000. Manajemen Sumber Daya Manusia, Penerbit Erlangga.

FATANSYAH. 2012. Basis Data. Bandung. Informatika Bandung.

FOWLER, MARTIN. 2004. UML Distilled. Yogyakarta. Andi Offset.

HUTAHEAN, JEPERSON. 2014. Konsep Sistem Informasi. Yogyakarta. Deepublish.

KADIR, ABDUL. 2013. Pengenalan Sistem Informasi. Yogyakarta. Andi.

LUTFI, A. A., \& WAHYUDI, R. (2017). Aplikasi Tracer Study Berbasis Website Responsive Pada Fakultas Pertanian Universitas Jendral Soedirman. Majalah Ilmiah INTI (Informasi Dan Teknologi Ilmiah), 13, 125-132.

MASRURI HILMI. 2014. Buku Pintar Android. Jakarta. Elex Media Komputindo.

NUGROHO ADI. 2010. Rekayasa Perangkat Lunak Berbasis Objek Dengan Metode USDP. Yogyakarta. Andi Offset.
PRESSMAN, ROGER S. 2010. Pendekatan Praktisi Rekayasa Perangkat Lunak. Yogyakarta. Andi.

PRESSMAN, ROGER. 2005. Software Engineering: a Practitioner's Approach. Sixth Edition. Mcgraw-Hill. Singapore.

RAHARJO BUDI. 2015. Belajar Otodidak Framework Codeigniter. Bandung. Informatika Bandung.

STATCOUNTER GLOBALSTATS. (2018). Operating System Market Share Indonesia July 2017 - July 2018. Diambil dari:

http://gs.statcounter.com/osmarketshare/all/indonesia

SUGIYONO. 2015. Metode Penelitian Pendidikan (Pendekatan Kuantitatif, Kualitatif dan R\&D). Bandung. CV Alfabeta

SUTABARI, TATA. 2012. Konsep Sistem Informasi. Yogyakarta. Andi.

WAHYUDI, R., UTAMI, E. AND ARIEF, M.R., 2016. Sistem Pakar E-Tourism Pada Dinas PariwisataDiy Menggunakan Metode Forward Chaining. DASI, 17(2), pp.67-75. 
Halaman ini sengaja dikosongkan 